\title{
Estimation of Truck Trips on Large-Scale Irrigation Project: A Combinatory Input-Output Commodity-Based Approach
}

\author{
Ackchai Sirikijpanichkul ${ }^{1}$, Sarintorn Winyoopadit ${ }^{2}$, and Chavalek Vanichavetin ${ }^{3}$ \\ ${ }^{1}$ Lecturer, Department of Civil Engineering, Faculty of Engineering, Kasetsart University, Bangkok, 10900, Thailand. \\ Email: fengacs@ku.ac.th (corresponding author). \\ ${ }^{2}$ Public Sector Development Officer, Office of the Public Sector Development Commission Thailand (OPDC), Bangkok, \\ 10300, Thailand. Email: sarintornw@gmail.com \\ ${ }^{3}$ Associate Professor, Department of Civil Engineering, Faculty of Engineering, Kasetsart University, Bangkok, 10900, \\ Thailand. Email: fengclv@ku.ac.th
}

\author{
Project Management \\ Received January 31, 2014; received revisions April 15, 2014; April 28, 2014; accepted May 10, 2014 \\ Available online May 30, 2014
}

\begin{abstract}
For the agricultural-based countries, the requirement on transportation infrastructure should not only be limited to accommodate general traffic but also the transportation of crop and agricultural products during the harvest seasons. Most of the past researches focus on the development of truck trip estimation techniques for urban, statewide, or nationwide freight movement but neglect the importance of rural freight movement which contributes to pavement deterioration on rural roads especially during harvest seasons. Recently, the Thai Government initiated a plan to construct a network of reservoirs within the northeastern region, aiming at improving existing irrigation system particularly in the areas where a more effective irrigation system is needed. It is expected to bring in new opportunities on expanding the cultivation areas, increasing the economy of scale and enlarging the extent market of area. As a consequence, its effects on truck trip generation needed to be investigated to assure the service quality of related transportation infrastructure. This paper proposes a combinatory input-output commodity-based approach to estimate truck trips on rural highway infrastructure network. The large-scale irrigation project for the northeastern of Thailand is demonstrated as a case study.
\end{abstract}

Keywords: Input-output, commodity-based, truck trips, rural roads.

\section{Introduction}

For the agricultural-based countries, the requirement on transportation infrastructure should not only be limited to accommodate general traffic but also the transportation of crop and agricultural products during the harvest seasons. Most of the past researches focus on the development of truck trip estimation techniques for urban, statewide, or nationwide freight movement but neglect the importance of rural freight movement which contributes to pavement deterioration on rural roads especially during harvest seasons. Recently, the Thai Government initiated a plan to construct a network of reservoirs within the northeastern region, aiming at improving existing irrigation system particularly in the areas where a more effective irrigation system is needed. It is expected to bring in new opportunities on expanding the cultivation areas, increasing the economy of scale and enlarging the extent market of area. As a consequence, its effects on truck trip generation needed to be investigated to assure the service quality of related transportation infrastructure.

The objective of this study is to propose the estimation technique of truck trips using a combinatory input-output commodity-based approach. It demonstrates how to turn each ton of crop produce into truck trips by taking various factors into account including cultivation factors, supply chain factors, and wider economics factors using the largescale irrigation project for the northeastern of Thailand is demonstrated as a case study.

\section{Overview of Thailand Northeastern Irrigation Project}

Although, Thailand is one of the largest agricultural countries, however the cultivation relies mostly on rainwater. The service area of the existing irrigation system is only within the boundary of dam catchment areas, whereas for the others, the demand for water is still immense. The northeastern region, where most farmland is contained, is facing a problem of inaccessible irrigation and insufficient water in some parts of the region. Such problem leads to unproductive cultivation areas during the harvest seasons, and finally ends up with drought areas. The problem of unproductive lands reduces the income and quality of life of the local people and is realized as a major cause of poverty in the region. In order to relieve the problem, the Thai Government proposes a grant for the provision of region-wide irrigation. 
The objective of region-wide irrigation planning is to expand the existing irrigation network so that the agricultural land can be cultivated productively throughout the year. According to the study done by the Department of Water Resources, the Ministry of Natural Resources and Environment, the project could expand the irrigation area coverage from the current 71.40 Million Rais to 104.60 Million Rais ( 1 hectare $=6.25$ Rais). As a result, the productive farmland will be increased significantly with a high productivity of the harvest crops. The consequence is the need of transportation of crops to local distribution centers or elsewhere, domestically and internationally.

The proposed irrigation network will cover 19 critical drought areas of the northeastern region and would result in sufficient water resource for cultivation all year round. The planned irrigation network for the northeastern region is presented in Fig. 1.

\section{Estimation of Truck Trips on Rural Road Network}

\subsection{Passenger and Freight Demand}

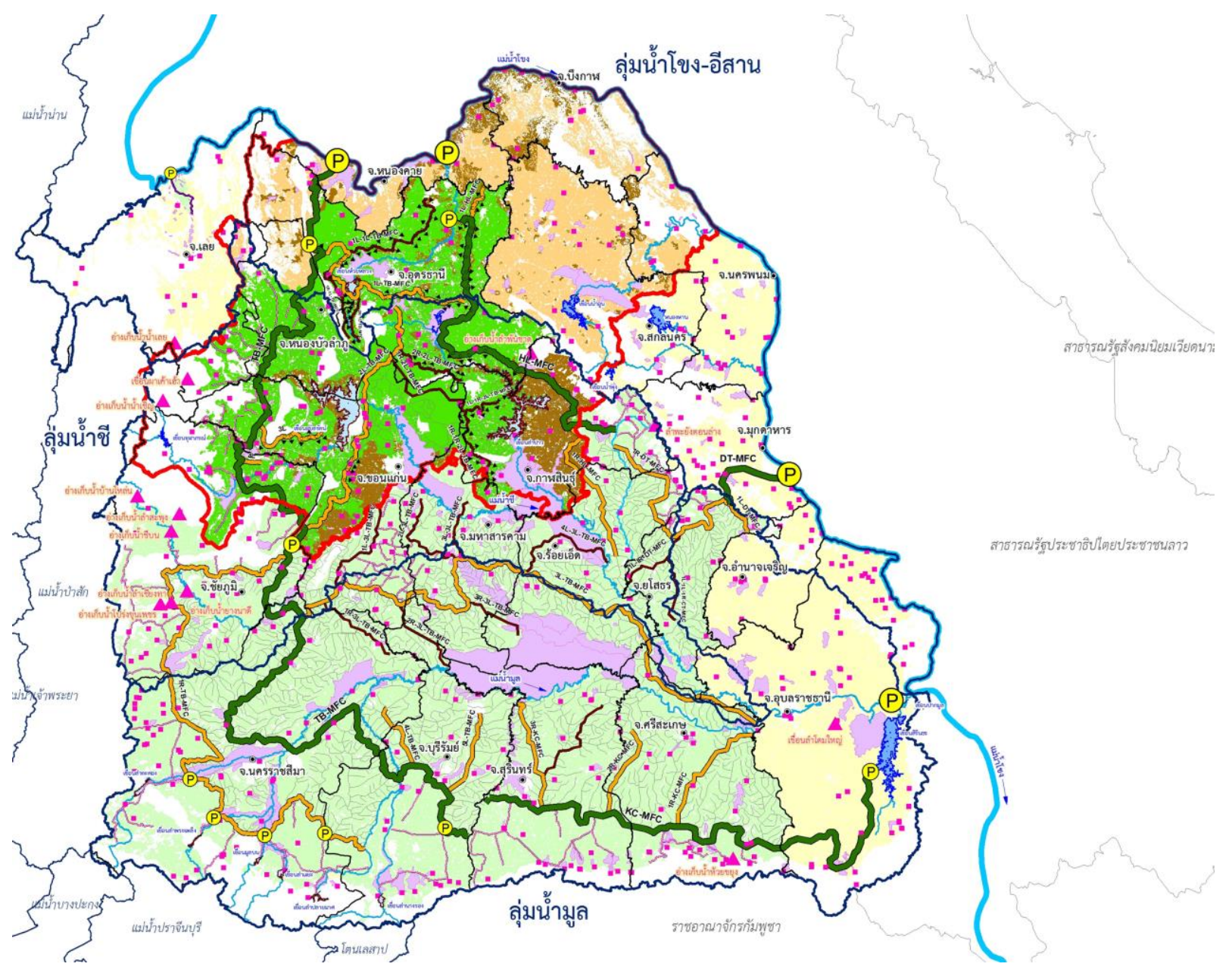

Legends: Planned Reservoir for Precipitation and the Mekong River in the Study Area; Planned for Precipitation and the Mekong River outside the Study Area ; Planned Reservoir for Precipitation in the Study Area; Planned

Reservoir for Precipitation outside the Study Area; $\square$ Existing Reservoir; Existing Irrigation Area; $\square$ Future

Development Area; — Watershed Boundary; - Study Area Boundary; — Province Boundary; $\checkmark$ Mainline

Waterway;_ Main Feeder Canal;_ Feeder Canal;_ Sub-feeder Canal; —— Mekong River Canal Link

Fig. 1. Region-wide irrigation network project in the northeastern

(Source: Department of Water Resources, Ministry of Natural Resources and Environment) 
- Location factors; freight is usually part of an industrial process. Therefore, the location of sources for inputs to a production process as well as the location of intermediate and final markets will determine the levels of freight movements.

- The range of products needed and produced is very high, much greater than a detailed segmentation of travel demand by person types and journey purposes.

- Physical factors; due to different characteristics and nature of raw materials and end products, there is a greater variety of vehicle types to match commodity classes than in the case of passenger transport.

- Operational factors. The size of the firm, its policy for distribution channels, and its geographical dispersion and so on, influence the possible use of different modes and shipping strategies.

- Geographic factors. The location and density of population may influence the distribution of end products.

- Dynamic factors. Seasonal variations in demand and production play an important role in changing freight movement pattern.

- Pricing factors. Prices are not, in general, published as appear in passenger fares as they are much more flexible and subject to negotiations and bargaining power.

\subsection{Decisions on Freight Transport Mode}

Freight transport is passive, that means freight cannot travel by itself but is transported by its carriers and service providers. Decisions on transport modes depend mostly on value density of the freight and distance (sirikijpanichkul, 2006). For example, truck dominates short-haul access to freight origins such as farms, mine, and so on, or freight destinations such as household, stores, markets, factories, and so on and also connects these freight origins or destinations with logistics nodes such as ports, airports, road-rail intermodal terminal, container yards, distribution centers, truck terminal and so on for intermodal transportation. For long-haul transport between logistics nodes, sea, air, rail, inland-waterway, pipeline dominates its role.

\subsection{Urban Highway and Rural Road Assessment}

Considering the supply chain of agricultural products, most of them have origins in the rural farming areas, harvest, and transport during harvesting season using trucks. Some fresh produces are transported to their markets for direct consumption. The others are needed to be processed at the processing plants such as rice mills, sugar mills, and flour mills, and so on, then the processed products are transported to their corresponding markets. Most agricultural products have low value-density, which means its unit cost per volume or weight is relatively low compared to other industrial goods or time-sensitive freight. Also they usually appear to be transported in-bulk rather than in container. Considering their characteristics as mentioned above, road transport especially on rural roads play an important role in transporting agricultural products from their origins to destinations. Planning and assessment of level of service of rural roads are unique and different from the practice adopted in urban highway according to the following reasons:

- Traffic impacts on rural roads are seasonal. Peak traffic occurs during harvesting seasons which is different from urban traffic that is congested all year round due to commuting trips.

- Rural households have more vehicles and are more likely to have older vehicles, especially pick-up trucks.

- Rural households account for more vehicle miles of travel with faster travel speed.

- The typical vehicle types using rural roads include automobiles, motorcycles, pickup trucks, farmerowned tandem axle and semi-trucks, farm combines, and farm tractors pulling various types of farm equipment. Other vehicle types include commercial trucks, garbage trucks, and school buses while most vehicles using urban roads include sedans, motorcycles, van and buses.

The evidences supporting the above arguments appear in Sebaaly et al. (2003), USDOT (2005); while some studies focus on rural road management including Anderson and Sessions (1991), Tolliver et al. (2011), Babcock and Alakshendra (2012); only a few focus on how seasonal effects impact traffic loading onto rural road network such as Kansas DOT (2009).

\subsection{Vehicle-Trip-Based and Commodity-Based Truck Trip Estimation}

Raothanachonkun et al. (2007) reviewed truck trip estimation techniques, usually in the form of OriginDestination matrix and classified them into vehicle-tripbased or commodity-based approaches. The former focuses on the flows of truck trips but overlooks the important characteristics of the shipments as pointed out by Holguin-Veras (2002). In addition, there are no distinctions between empty and loaded trips (HolguinVeras and Thorson, 2003). The later approach gets more attentions as it resolves the problems of the former but still has a limitation related to its inability to model empty trips (Holguin-Veras and Thorson, 2003; Holguin-Veras et al., 2005) which is later resolved by Chin and Hwang (2006) Holguin-Veras and Zorrilla (2006) and Raothanachonkun et al. (2007) who developed empty truck trips model based on nth order rather than zero order trip chain (round trip). Attempt to reduce empty truck trips are dominated by reverse logistics work as in Hosseini et al. (2014) but a few have been applied to transport planning area. Thus more research studies on the subject are encouraged to reduce overall logistics cost.

\subsection{Input-Output Economics Model}

Wassily Leontief who won the Noble prize in economics in 1973 proposed a model for the economics of a whole country or region. In the model there are $n$ industries producing $\mathrm{n}$ different products such that the input equals the output or, in other words, consumption equals production. The Leontief input-output model can be classified into.

- Open model of which some production consumed internally by industries, rest consumed by external bodies and. 
- Close model of which entire production consumed by industries.

The open model is formulated as in Eq. (1) (Dietzenbacher and Lahr, 2004),

$$
\mathrm{X}=\mathrm{TX}+\mathrm{E}
$$

Where $\mathrm{T}$ is called the input-output or technology matrix, $\mathrm{E}$ is the external demand vector and $\mathrm{X}$ is the production level vector under the condition that $\mathrm{T}$ and $\mathrm{E}$ is not zero matrix and vector, respectively.

The Leontief input-output model can be adopted at the local, region or national level. For the national level, the wider economics is taken into account and all economic activity is assigned to one of two types of sectors: production or final demand. Production sectors such as agriculture, manufacturing, services, trade, and so on represent all establishments in the region producing a specific product or service. Final demand may include households, government, foreign trade, or inventory. These are sectors where the level of activity is assumed to be determined by forces external to the model, such as a government policy (Otto and Johnson, 1993).

\section{Research Methodology}

Research methodology as shown in Fig. 2 begins with classification and clustering. For each fresh product, annual crop harvested can be estimated by multiplying harvest area with productivity. It is noted that the harvest area is expected to be expanded significantly if the irrigation project is developed. Adjusted by seasonal factors, peak-season crop harvested and transported can be determined. Some of the fresh products are transported to the markets for direct consumption while the others are transported to the processing mills or plants. The processing of each crop and relevant conversion factor are needed to be identified to convert the quantity of crop harvested into processed products to be delivered to various market segments as shown in Table 1.

The growth of each product by market segment is estimated based on historical trade data and the future economic trend. However, on the rural farming areas, most of the truck trips are dominated by intraregional transport, and export. Then, the effects of project development on freight movement in tonnage of freight and wider economics in tonnage of freight and passengers are assigned into each transport mode based on the national modal split model. Tonnage of freight movements on road are converted into truck trips using the average load factor and percentage of empty truck trips based on assumptions of direct delivery of full truck load (round trip). Non-truck traffic from the background traffic and effects on wider economics are converted into passenger car equivalent unit (PCU) using corresponding PCU factors. Compared with the road link capacity, the volume to capacity ratio and level of service of each road link can be concluded.

\section{Research Outcomes}

\subsection{Cultivation Factors}

\subsubsection{Cultivation zoning}

Since the expansion of the irrigation system in the area leads to an increase of the overall cultivation area, the analysis of cultivation areas, productivity and harvesting seasons is required for freight demand forecasting. In this study, the above factors have been analyzed and provided by the Department of Water Resources. The crops for this particular study are based on the top produced crops of the region which including rice, rubber, sugar cane, palm and corn. The summary of the cultivation zoning are presented in Fig. 3 to Fig. 7.

\subsubsection{Cultivation area}

The forecasted cultivation area for each type of crops by province is summarized in Table 2. This information is the primary input into the estimation of additional truck trips on the rural road network.

\subsubsection{Harvesting seasons}

The expansion of the cultivation after the new irrigation network is presented in the previous section, however, each crop has different cultivation and harvesting seasons. Therefore, to reflect the peak freight transport demand, the analysis of the freight demand is needed to be considered on the monthly basis as shown in Eq. (2),

$$
\Sigma \mathrm{i} \text { VMi }=\Sigma \mathrm{i}(\mathrm{Pi} \text { x A i / M i) }
$$

where

$\mathrm{VM} \mathrm{i}$ is the total production of crop type $\mathrm{i}$ in the month (in tons/month)

$\mathrm{Pi}$ is the production rate of crop type $\mathrm{i}$ per rai per annum (in tons / rai-year)

$\mathrm{Ai}$ is the cultivation area of crop type $\mathrm{i}$ (in rai)

$\mathrm{Mi}$ is the number of months its harvesting period of crop i (months/year)

Table 1. Market segment of truck trips

\begin{tabular}{ccc}
\hline Onigin & Internal & External \\
\hline External & $\begin{array}{c}\text { Intraregional } \\
\text { Transport }\end{array}$ & Export \\
\hline External & Import & Transshipment \\
\hline
\end{tabular}

Table 2. Forecast of the cultivation area in the northeastern

\begin{tabular}{ccc}
\hline Province & & Study Area \\
\hline \multirow{2}{*}{ Rice } & pre- & 28.0 \\
& post- & 30.5 \\
\hline \multirow{2}{*}{ Corn } & pre- & 1.3 \\
& post- & 1.3 \\
\hline \multirow{2}{*}{ Palm } & pre- & 0.6 \\
& post- & 0.6 \\
\hline \multirow{2}{*}{ Sugar Cane } & pre- & 11.4 \\
& post- & 12.1 \\
\hline \multirow{2}{*}{ Rubber } & pre- & 8.3 \\
& post- & 8.5 \\
\hline
\end{tabular}

(Source: Department of Water Resources, Ministry of Natural Resources and Environment) Unit: Million Rais 
40 Sirikijpanichkul, A., Winyoopadit, S., and Vanichavetin, C.

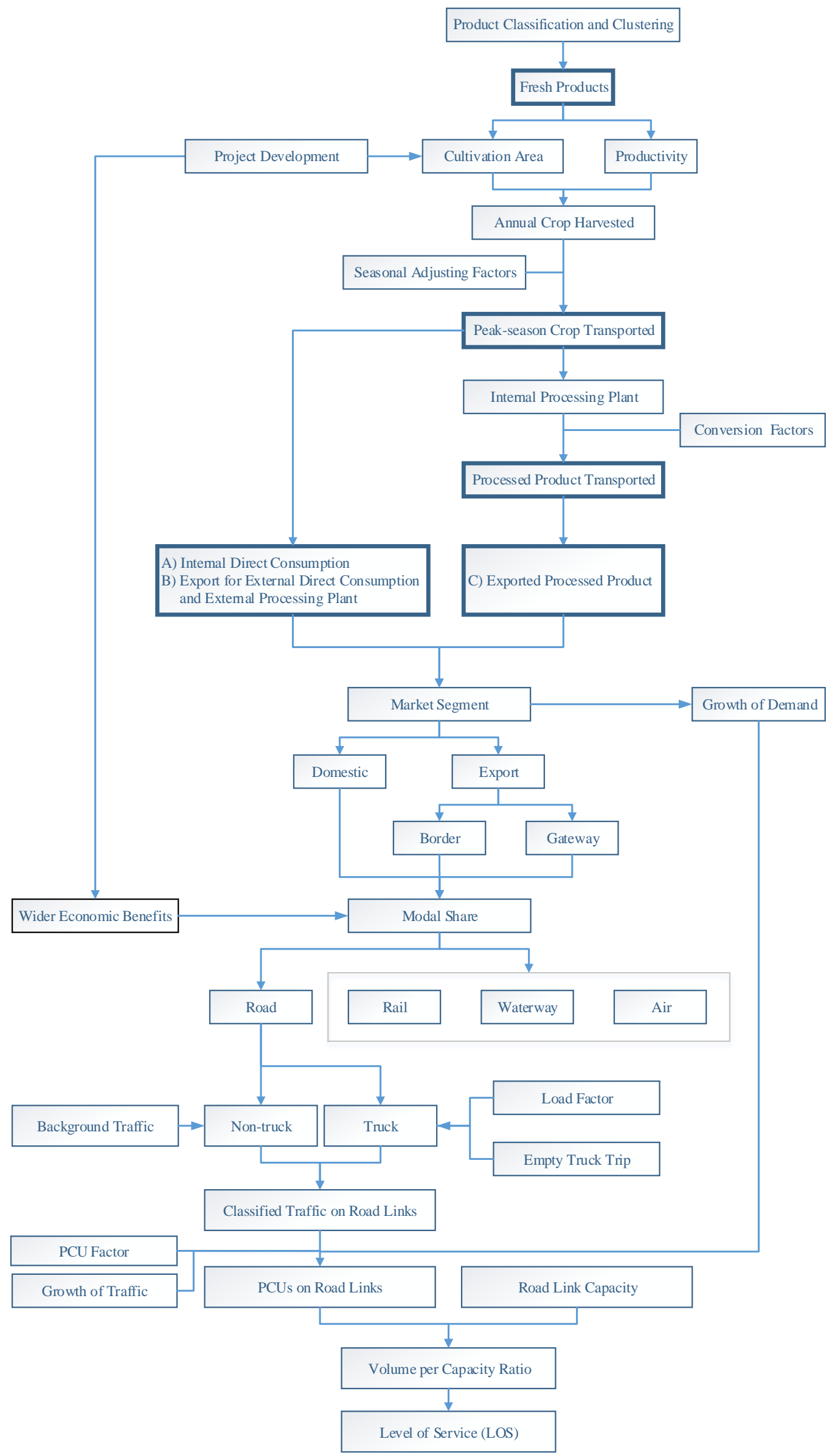

Fig. 2. Research methodology 


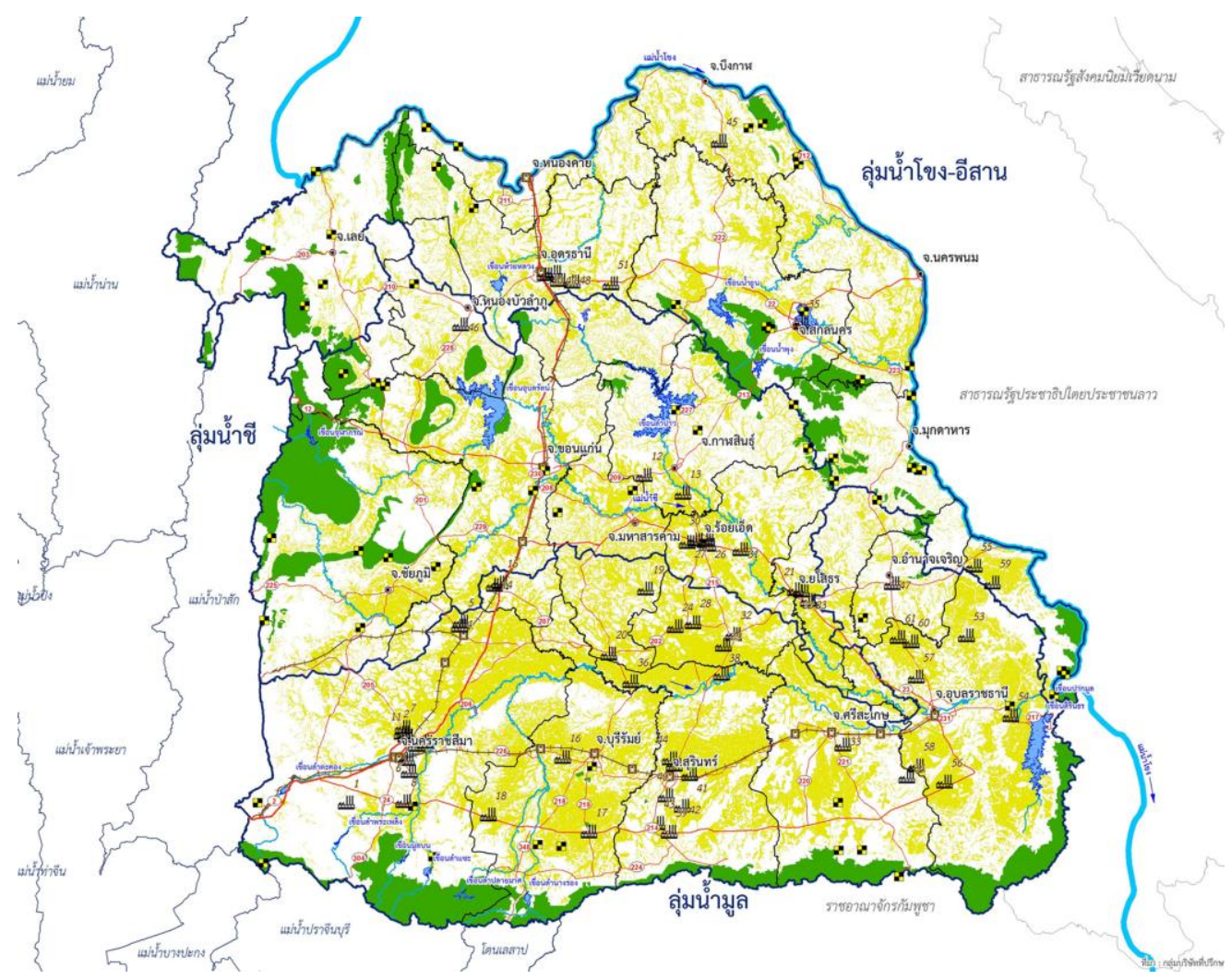

Legends: __ Waterway; Reservoir; Cultivation zone for rice

Fig. 3. Cultivation zones for rice in the northeastern

(Source: Department of Water Resources, Ministry of Natural Resources and Environment)

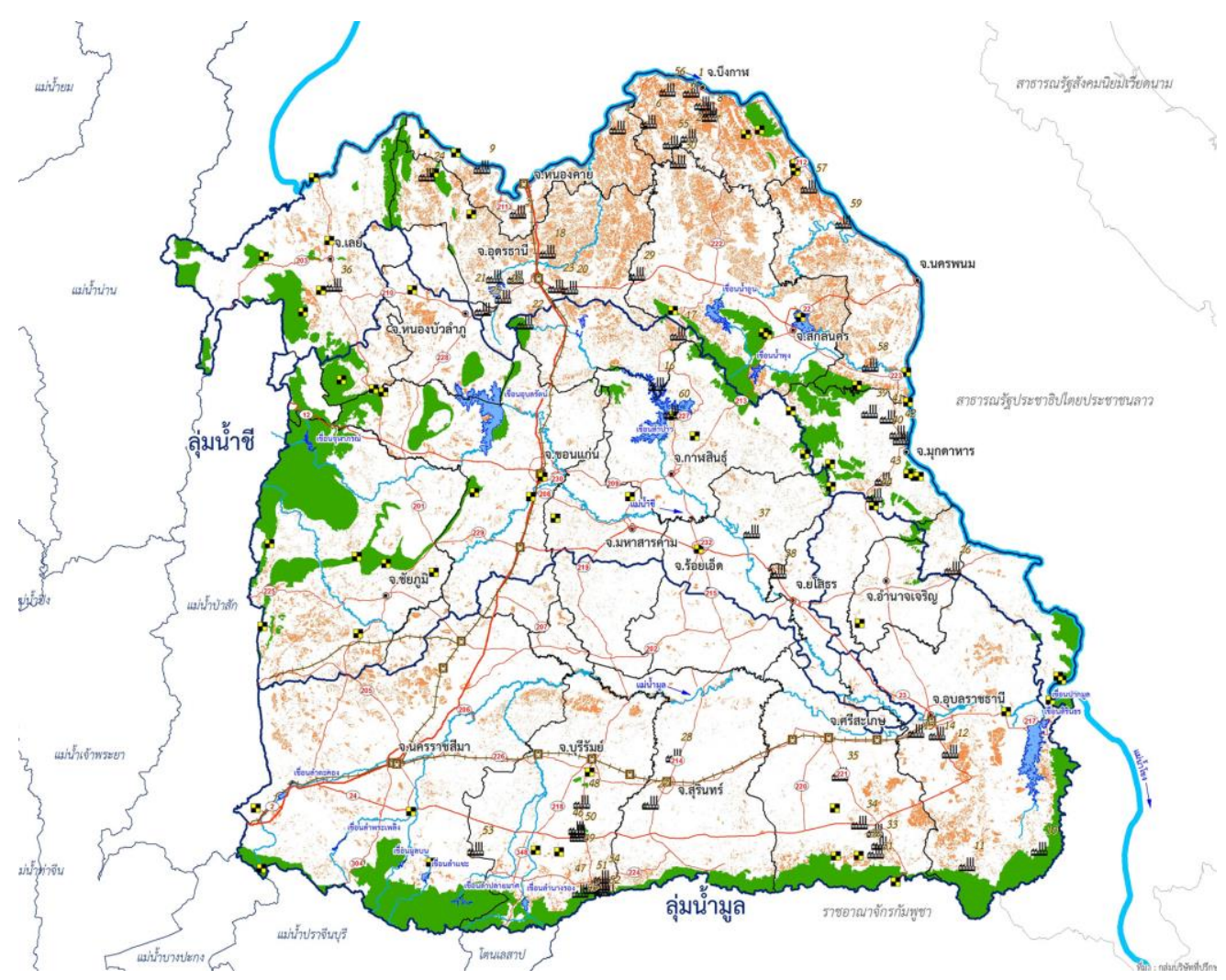

Legends: __ Waterway; Reservoir;_ Cultivation zone for rubber

Fig. 4. Cultivation zones for rubber in the northeastern

(Source: Department of Water Resources, Ministry of Natural Resources and Environment) 
42 Sirikijpanichkul, A., Winyoopadit, S., and Vanichavetin, C.

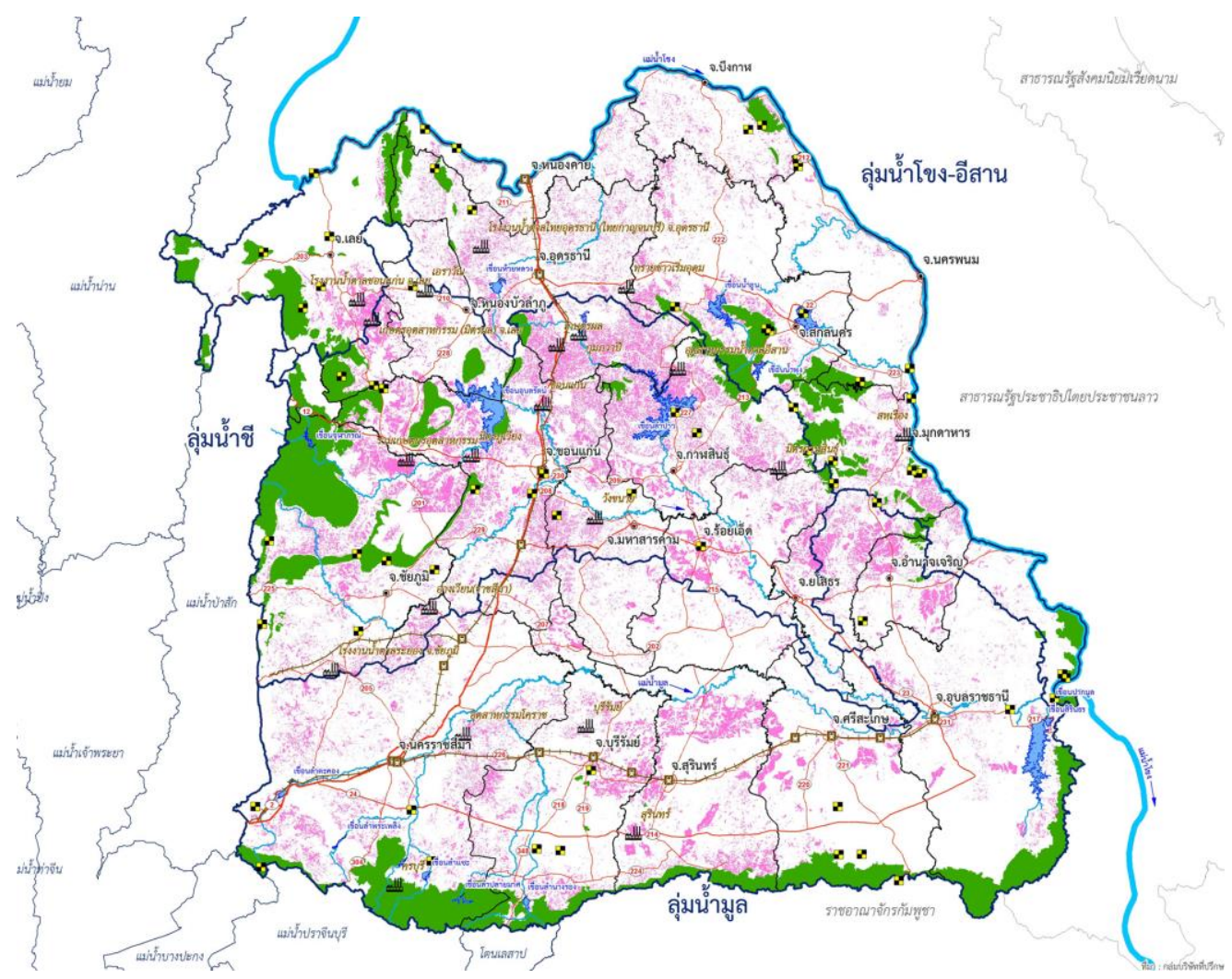

Legends: __ Waterway; Reservoir; Cultivation zone for sugar cane

Fig. 5. Cultivation zones for sugar cane in the northeastern

(Source: Department of Water Resources, Ministry of Natural Resources and Environment)

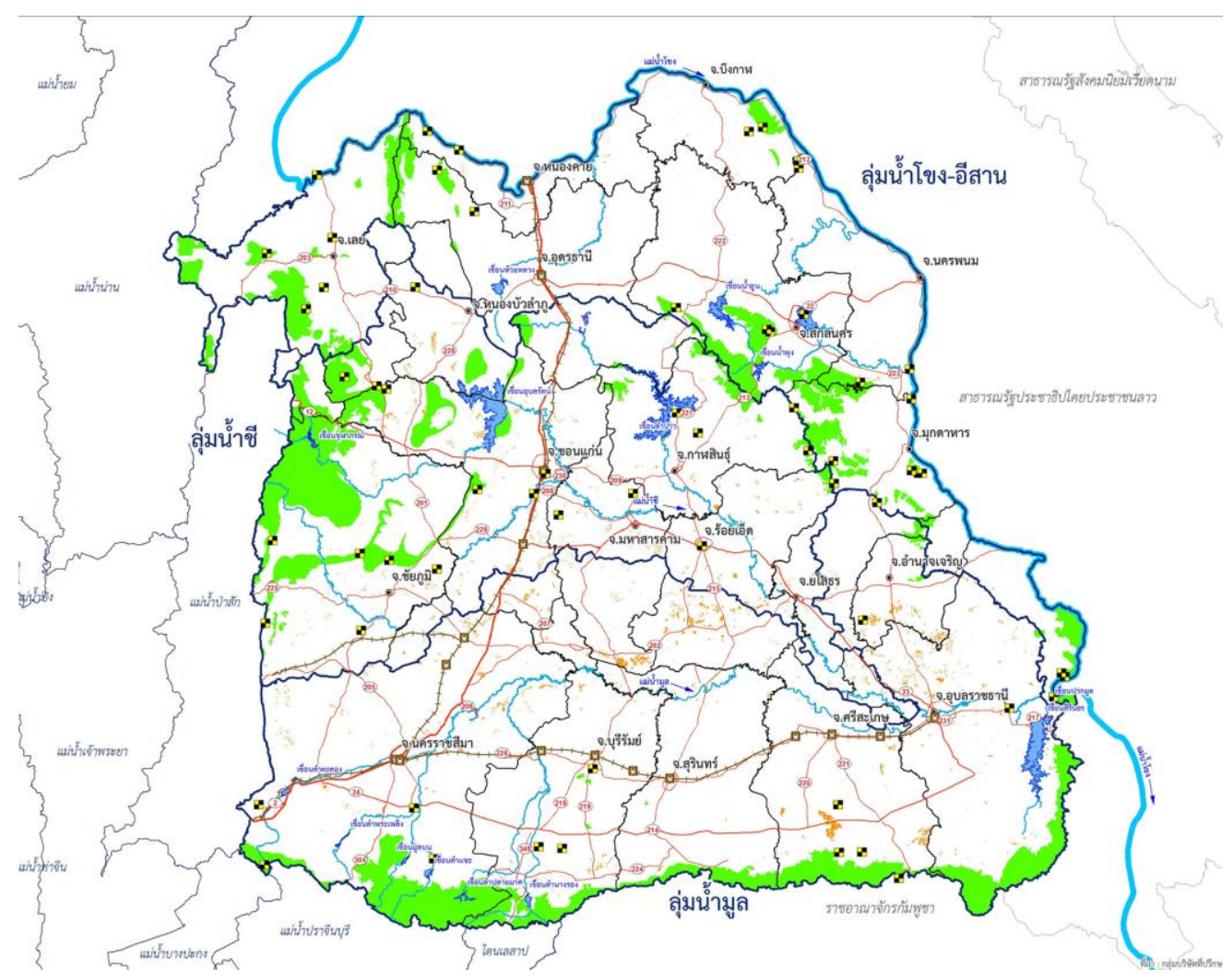

Legends: __ Waterway; Reservoir;__ Cultivation zone for palm

Fig. 6. Cultivation zones for palm in the northeastern

(Source: Department of Water Resources, Ministry of Natural Resources and Environment) 


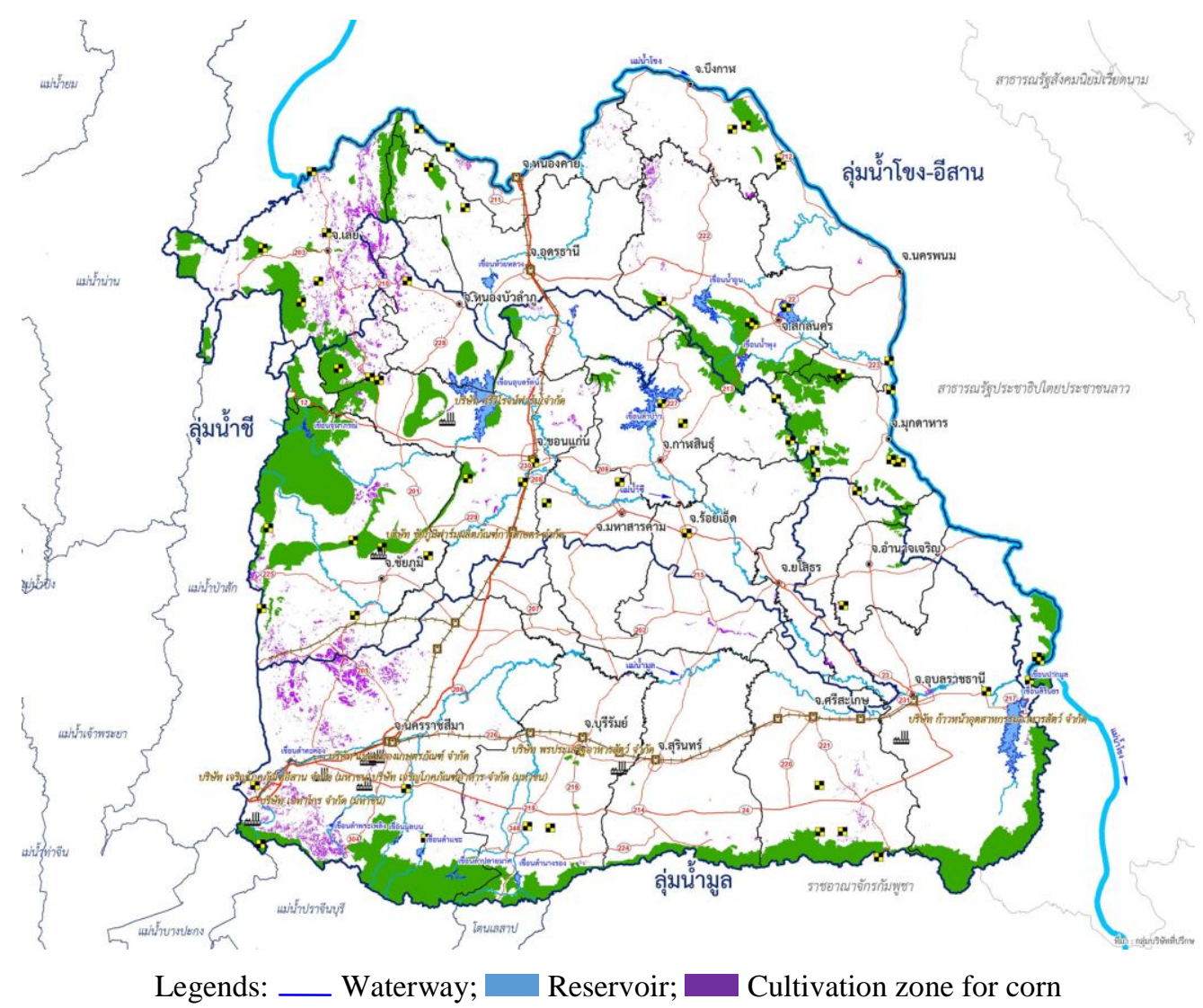

Fig. 7. Cultivation zones for corn in the northeastern

(Source: Department of Water Resources, Ministry of Natural Resources and Environment)

\subsubsection{Load factors and empty truck trips}

The forecasted crop production, the harvest seasons and its cultivation area are analyzed by province to determine the monthly agricultural output. It is then distributed to the potential destinations including, domestic and international gateways according to its distribution channels. For empty truck trip calculation, this research assumes zero order trip chain (round trip) for cultivation areas. Therefore, there are two trips generated when transporting the fresh product from the cultivation area (one empty truck trip for access and one full truck load for egress) but transport of fresh product to processing mills require only one trip for access but the other full truck load for transporting processed product. Each freight movement is divided by the average load factor for each crop as shown in Fig. 8, then the forecasted truck demand can be derived by Eq. (3)

$$
\mathrm{T} \text { ij }=\text { Ii } \Sigma \mathrm{i}(\mathrm{VM} \mathrm{i}) / \mathrm{Lij}
$$

where

Tij is the total traffic for transporting crop i by truck type $\mathrm{j}$ in the month (vehicles/month)

Ii is the index of empty truck trips;

2 for cultivation areas,

1 for processing mills / plants.

$\mathrm{VMi}$ is the total production of crop type in the month (tons/month)
Lij is the average load factor of transporting crop $\mathrm{i}$ by truck type $\mathrm{j}$ in the month (tons/vehicle)

\subsection{Supply Chain Factors}

Apart from direct consumption, some fresh products are transported to processing mills or plants for converting to processed products. The volume of freight after the process can be reduced subject to amount of waste or residues. Thus the conversion factor is needed to transform the volume of the fresh product into the processed products as shown in Eq. (4).

$$
\Sigma \mathrm{i} \mathrm{PM} \mathrm{i}=\Sigma \mathrm{i}(\mathrm{VM} \text { i } \times \mathrm{F} \text { i) }
$$

where

PM $i$ is the total production of processed product by crop type $\mathrm{i}$ in the month (in tons/month)

$\mathrm{VM} \mathrm{i}$ is the total production of crop type $\mathrm{i}$ in the month (in tons/month)

$\mathrm{Fi}$ is the conversion factors of crop type $\mathrm{i}$ (in tons per ton of crop)

Examples of conversion factors for some types of crop are as follows (DOA, 2013):

- 1 ton of paddy can produce 660 kilograms of rice, 110 kilograms of rice bran, and 230 kilograms of rice husk. 
- 1 ton of sugar cane can produce 110 kilograms of sugar, 60 kilograms of molasses, and 830 kilograms of by-products such as bagasse and filter mud.

- 1 ton of cassava can produce 400 kilograms of cassava chip or shredded, or 900 kilograms of cassava pellet, 200 kilograms of cassava flour or tapioca flour and 90 kilograms of cassava meal or cassava waste.

\subsection{Wider Economics Factors}

Apart from increase in truck trips from direct consumption and supply chain factors, the large-scale irrigation projects can induced more passenger travels and freight transport demand based on wider input-output economics model. For example, more processed mill/plants may be established in the new irrigation area and more commuting trips or more commercial truck trips to deliver consumption products can be expected.

However in this research, the wider economics factors are not taken into account.

\subsection{Transport Demand Forecast}

According to Thailand's exporting statistics for agricultural products (OAE, 2013), an average of 30 percent of crop product is consumed domestically, except for rubber which is 100 percent export. For the domestic demand, the traffic is being distributed to the target distribution centers or local industrial zones subject to the supply chain of particular products. The rest is being transported to the international gateways such as deep sea ports or international borders for exporting.

\subsubsection{Domestic demand}

As described, the domestic demand of 30 percent except rubber is distributed locally. The target destinations for domestic use of the product are assigned based on national consumption. The distribution of raw product firstly designated to the local factories for processing. For example, rice product is firstly distributed to the local rice mills and packing stations. The average weight proportion of milled and un-milled rice is used to calculate the net weight of the rice output. Since the major distribution centers for national consumption are located in the central region approximately in the vicinity provinces around Bangkok, the transport route assigned are the major highways to the region described. The products analyzed in this study including rice, corn, palm, sugar cane and rubber. Table 3 presents the example of the distribution of additional traffic demand for domestic consumption.

\subsubsection{External demand}

The concept of the external demand is based on the assumption that there is an international demand of exported products. The external demand is assumed to be 70 percent of the total production and is distributed to the highway network and intermodal facilities within the region. Because, most of the export destinations are dominated by the Europe, USA, East Asia and Japan, the final destination of the external demand is mainly the deep sea ports in the eastern seaboard. The proportion of 70:30 estimation of the modal spit between road and rail transport studied by the Office of Transport and Traffic
Policy and Planning is used to split the demand by mode for each destination. The distribution of additional traffic demand to the major road network leading to Thailand's international gateways can be summarized in Table 4 .

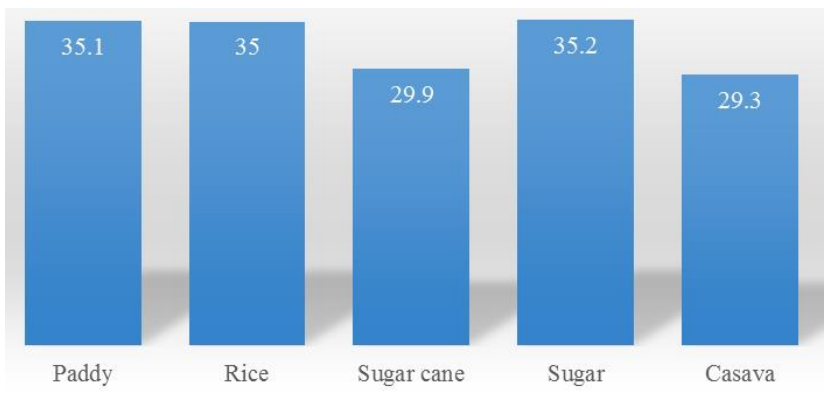

Fig. 8. Average load factor by crop type

(Parnsomboon, 2000)

Table 3. Examples of the distribution of additional traffic demand for domestic consumption

\begin{tabular}{ccc}
\hline & & Domestic \\
\hline \multirow{2}{*}{ Rice } & 1,000 Rai & 2,488 \\
& vehicle/ day & 192 \\
Corn & 1,000 Rai & 24 \\
& vehicle/ day & 18 \\
\multirow{2}{*}{ Palm } & 1,000 Rai & 49 \\
& vehicle/ day & 5 \\
Sugar Cane & 1,000 Rai & 759 \\
& vehicle/ day & 924 \\
Rubber & 1,000 Rai & 134 \\
& vehicle/ day & 20 \\
\hline
\end{tabular}

Table 4. Examples of additional traffic, designated to the international gateways

\begin{tabular}{ccc}
\hline & & External \\
\hline \multirow{2}{*}{ Rice } & 1,000 Rai & 2,488 \\
& vehicle/ day & 448 \\
\multirow{2}{*}{ Corn } & 1,000 Rai & 24 \\
& vehicle/ day & 20 \\
Palm & 1,000 Rai & 49 \\
& vehicle/ day & 23 \\
Sugar Cane & 1,000 Rai & 759 \\
& vehicle/ day & 2,159 \\
Rubber & 1,000 Rai & 134 \\
& vehicle/ day & 20 \\
\hline
\end{tabular}




\subsection{Traffic Impact Assessment}

From the forecast of domestic and external demand, the additional truck traffic is combined with other background traffic that is not related to additional crop harvest from the project. The background traffic needed to be daily averaged from the traffic collected throughout the year technically called Annual Average Daily Traffic (AADT). The combined traffic demand to be distributed into the road network but needed to be converted into a unified passenger car equivalent unit (PCU) using a so called PCU factors as each type of vehicles occupies different amount of space on the road. Typically a car, a truck or a bus, and a motorcycle have 1, 2.5, and 0.33 PCUs, respectively. The distributed traffic into the highway network is used in analyzing the traffic impact of the project. The average growth rate of the region is used to determine the 10-year future demand as the pre-implementation traffic demand. By comparing pre- implementation and postimplementation traffic, the traffic impact of the project could be assessed.

According to the Highway Capacity Manual (National Research Council (U.S.), 2010), the 'capacity' of the facility is defined as the maximum amount of traffic that the transportation infrastructure can carry under prevailing conditions of geometry, traffic mix and location. The Level of Service (LOS) is defined as a qualitative measure that describes traffic conditions in term of speed, travel time, freedom to maneuver, comfort, convenience, traffic interruptions, and safety. For a highway section, the LOS can be explained by the volume-to-capacity ratio (V/C) which varies from a low of 0 (free flow) to values sometimes greater than 1.0 (severely/heavily congested). The suggested levels of service (LOS) and related V/C by the Highway Capacity Manual (National Research Council (U.S.), 2010) is as shown in Table 5.

It is noted that since traffic demand relies on the type of crops cultivated in each sub-area and harvesting seasons, the impact is assessed on the monthly basis. For each highway section, the results during the critical month are used to determine the impact to the road network. The example of traffic impacts on road network during its critical month is presented in Table 5. From the results, it is seen that although the region-wide irrigation project coverage area largely covers the agricultural land in the northeastern region. The impact of the increase in crop transport demand on road network is not significant. It is noted that the highway sections analyzed in this study are mostly the inter-city highway which function as a linkage between provinces or as a regional highway network. Therefore, the designed capacity of the highway network is quite high while the general traffic demand is relatively low.

However, Table 6 shows that there are some of the highway sections which consist of the Highway No.2 section 1000 and Highway No.12 section 1602 that both pre- and post-implementation LOS is significantly low at LOS F. This is because the former is the major linkage between Khonkaen City Center and Udornthani which generally accommodates already high traffic demand. The latter section, Highway No.12 section 1602, links between Khonkaen City and Chumpae District which is one of the most popular residential areas. It is noted that in term of location on the overall network, Khonkaen is one of the biggest cities located in the heart of the northeastern region. Avoiding this part of the road network when traveling from the north and the east of this region would be very difficult. Therefore the combination of high background traffic demand and additional traffic from agricultural products highly affects highway sections' V/C.

\section{Conclusions and Recommendation}

This paper demonstrates the method of estimation of truck trips on large-scale irrigation project. A combinatory input-output commodity-based approach is adopted that take into account cultivation factors, supply chain factors, and wider economics factors using the large-scale irrigation project for the northeastern of Thailand is demonstrated as a case study. Since the demand for transporting crops varies across the harvest seasons, the demand is needed to be estimated on month by month basis. The estimation of traffic demand also based on supply chain and distribution channels of each crop. However, wider-economic factors are not taken into account and recommended for further research investigation.

\section{Acknowledgements}

The authors would like to express their gratitude to the Department of Water Resources, Ministry of Natural Resources and Environment for their courtesy in valuable data and information used in this research.

Table 5. Level of service (LOS) and vehicle per capacity $(\mathrm{V} / \mathrm{C})$ ratio

\begin{tabular}{|c|c|c|}
\hline LOS & V/C Ratio & Description \\
\hline A & $0.00-0.35$ & $\begin{array}{l}\text { Free flow. No traffic interruption. } \\
\text { Best operating conditions. }\end{array}$ \\
\hline B & $0.35-0.58$ & $\begin{array}{l}\text { Reasonably free-flow with some } \\
\text { interruption. }\end{array}$ \\
\hline $\mathrm{C}$ & $0.58-0.75$ & $\begin{array}{l}\text { Constrained constant flow below } \\
\text { speed limits, with additional } \\
\text { attention for safe operations. }\end{array}$ \\
\hline $\mathrm{D}$ & $0.75-0.90$ & $\begin{array}{l}\text { Approaching unstable flow. } \\
\text { Severely restricted in } \\
\text { maneuverability. }\end{array}$ \\
\hline $\mathrm{E}$ & $0.90-1.00$ & Unstable flow near capacity. \\
\hline $\mathrm{F}$ & $>1.00$ & $\begin{array}{l}\text { Heavily congested flow and } \\
\text { traffic demand exceeding } \\
\text { capacity. Worst operating } \\
\text { conditions. }\end{array}$ \\
\hline
\end{tabular}


Table 6. Examples of traffic impacts on road network during the critical month

\begin{tabular}{ccccccc}
\hline Highway No. & \multirow{2}{*}{ Section } & Capacity & \multicolumn{2}{c}{ Pre- Project Implement } & \multicolumn{2}{c}{ Post- Project Implement } \\
\cline { 4 - 6 } & & & V/C & LOS & V/C & LOS \\
\hline 12 & 1801 & 7200 & 0.30 & A & 0.40 & A \\
12 & 1802 & 7200 & 0.18 & A & 0.24 & A \\
214 & 100 & 2400 & 0.56 & A & 0.75 & C \\
2 & 1000 & 7200 & 1.29 & F & 1.73 & F \\
2 & 1101 & 7200 & 0.25 & A & 0.33 & A \\
12 & 1602 & 7200 & 1.31 & F & 1.76 & F \\
208 & 101 & 2400 & 0.72 & C & 0.97 & E \\
201 & 600 & 7200 & 0.16 & A & 0.21 & A \\
225 & 800 & 7200 & 0.09 & A & 0.12 & A \\
201 & 300 & 7200 & 0.19 & A & 0.25 & A \\
202 & 202 & 2400 & 0.17 & A & 0.22 & A \\
22 & 700 & 7200 & 0.22 & A & 0.30 & A \\
212 & 1100 & 7200 & 0.19 & A & 0.25 & A \\
212 & 1001 & 7200 & 0.22 & A & 0.29 & A \\
2 & 300 & 14400 & 0.28 & A & 0.37 & A \\
2 & 500 & 14400 & 0.51 & A & 0.68 & B \\
2 & 600 & 7200 & 0.36 & A & 0.48 & A \\
226 & 101 & 7200 & 0.24 & A & 0.32 & A \\
24 & 201 & 7200 & 0.32 & A & 0.43 & A \\
304 & 904 & 7200 & 0.32 & A & 0.43 & A \\
\hline
\end{tabular}

\section{References}

Anderson, J. and Sessions, J. (1991). Managing low volume road systems for intermittent use, Transportation Research Record, 1291(1), 224-230.

Babcock, M. W. and Alakshendra, A. (2012). Methodology to measure the benefits and costs of rural road closure: A Kansas case study, Journal of the Transportation Research Forum, 51(1), 111-130.

Chin, S. and Hwang, H. (2006). Converting Freight Flow Information to Truck Volumes. Proceedings of the $85^{\text {th }}$ Transportation Research Board, Washington D.C.

Dietzenbacher, E. and Lahr, M. L. (Eds) (2004). Wassily Leontief and Input-Output Economics. Cambridge: Cambridge University Press.

Holguin-Veras, J. (2002). Reveal preference analysis of the commercial vehicle choice process, Journal of Transportation Engineering, 128(4), 336-346.

Holguin-Veras, J. and Thorson, E. (2003). Modeling commercial vehicle empty trips with a first order trip chain model, Transportation Research Part B, 37(2), 129-148.

Holguin-Veras, J., Zorrilla, J. C., and Thorson, E. (2005). Modeling Commercial Vehicle Empty Trips, Theory, and Application. Proceedings of the $16^{\text {th }}$ International Symposium on Transportation and Traffic Theory, 585-607.

Holguin-Veras, J. and Zorrilla, J.C., and Thorson, E. (2006). A First Approximation to Longitudinal
Modeling of Commercial Vehicle Empty Trips. Proceedings of the $85^{\text {th }}$ Transportation Research Board, Washington D.C.

Hosseini, M. R., Chileshe, N., Rameezdeen, R., Lehmann, S. (2014). Reverse logistics for the construction industry: Lessons from the manufacturing context, Journal of Engineering, Project, and Production Management. [In Press]

Verzuh, E. (2008). The Fast Forward MBA in Project Management. Hoboken, New Jersey: Wiley and Sons, $55-60$.

Ortuzar, J. de D. and Willumsen, L. G. (1996). Modelling Transport, $2^{\text {nd }}$ Ed, John Wiley \& Sons, Chichester.

Otto, D. M. and Johnson, T. G. (Eds) (1993). Microcomputer-based Input-Output Modeling: Applications to Economic Development. Boulder, CO: Westview Press. 228 pp.

Parnsomboon, N. (2000). Impacts on Changes in Truck Load Limitations on Highway Engineering. Thesis, Chulalongkorn University, Bangkok (In Thai).

National Research Council (U.S.). (2010) HCM 2010: Highway Capacity Manual, Transportation Research Board, Washington, D.C.

Kansas Department of Transportation (2009). Impacts of Kansas ethanol production on Kansas ttransportation. Technical Report, Topeka, Kansas.

Raothanachonkun, P., Sano, K., Wisetjindawa, W., and Matsumoto, S. (2007). Truck trips origin destination using commodity based model combined with an 
empty trip model. Proceedings of the 86th Transportation Research Board Annual Meeting, Washington DC.

Sebaaly, P. E., Siddharthan, R., and Huft, D. (2003). Impact of heavy vehicles on low volume roads, Transportation Research Record, 1819 (2), 228-235.

Sirikijpanichkul, A. and Ferreira, L. (2006). Contestable freight trends and implication for governments: Working Paper 1. Queensland University of Technology (QUT), Brisbane.

Tolliver, D., Dybing, A., Lu, P., and Lee, E. (2011). Modeling investments in county and local roads to support agricultural logistics, Journal of the Transportation Research Forum, 50 (2), 101-115.

US Department of Transportation (2005). Urban and rural travel behavior, Section VII, National Household Travel Survey (NHTS). Retrieved from http://www. fhwa.dot.gov/policy/ohim/hs05/national_household_i nfo.htm on March 31, 2014.

Department of Argriculture (2013). Conversion factors of agricultural crop (in Thai) Retrieved from http://www.doa.go.th/ on March 31, 2014.

Office of Agricultural Economics (2013). Thailand's exporting statistics for agricultural products (in Thai) Retrieved from http://www.oae.go.th/ewtadmin/ewt/ oae_web/download/journal/trends2556.pdfon March $31,2014$.

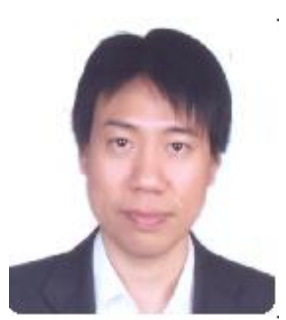

Dr. Ackchai Sirikijpanichkul is a full-time lecturer at Department of Civil Engineering, Faculty of Engineering, Kasetsart University, with memberships of Transport Planning Society (TPS), United Kingdom in 2008, Thai Society for Transportation and Traffic Studies (TSTS) in 2000 and Registered Professional Engineer, Engineering Institute of Thailand (EIT) since 1998. He is also working as a program coordinator of Kasertsart University Rail Engineering Research Group (KU-Rail). His research interests include Urban Mass Transportation Planning, Freight and Logistics, Transportation Demand Modeling, Decision Support Systems, Green Transport and Incident/ Disaster Management.

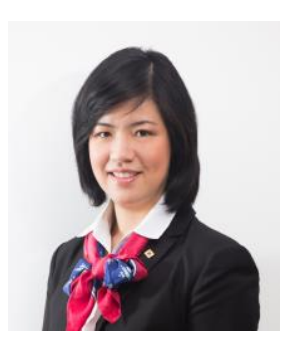

Dr. Sarintorn Winyoopadit is Public Sector Development Officer, Office of the Public Sector Development Commission Thailand (OPDC), with memberships of Transport Planning Society (TPS), United Kingdom in 2008, Thai Society for Transportation and Traffic Studies (TSTS) in 2001 and Registered Professional Engineer, Engineering Institute of Thailand (EIT) since 1999. She is also an advisor to Kasertsart University Rail Engineering Research Group (KU-Rail). Her research interests include Traffic Management, Intelligent Transport System, Transportation Demand Modeling, Traffic Safety Study and Rail Transit Planning.

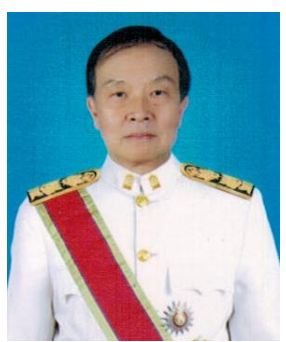

Associate Professor Chavalek Vanichavetin is an excellency lecturer at Department of Civil Engineering, Faculty of Engineering, Kasetsart University, with memberships of Registered Professional Engineer, Engineering Institute of Thailand (EIT). His research interests include Traffic Engineering, Transport Engineering, and Transport Planning. 